Bangladesh J. Bot. 42(2): 239-245, 2013 (December)

\title{
EFFECTS OF PARAQUAT-INDUCED OXIDATIVE STRESS ON ANTIOXIDANTS AND CHLOROPHYLL FLUORESCENCE IN STAY-GREEN WHEAT (TRITICUM AESTIVUM L.) FLAG LEAVES
}

\author{
Li Zhang, Junbo Chen, Huaiyu Zhang, Zhenglong Ren and Peigao Luo* \\ State Key Laboratory of Plant Breeding and Genetics, Sichuan Agricultural University, \\ Chengdu 611130, China
}

Key words: Paraquat, Wheat (Triticum aestivum L.), Reactive oxygen species, Chlorophyll fluorescence, Malondialdehyde

\begin{abstract}
Paraquat, a highly toxic herbicide, induces the production of reactive oxygen species in the cell. Paraquat resistance in stay-green wheat (Triticum aestivum L.) was investigated. Two cultivars, CN12 and CN17, were found to have a higher photo-oxidative resistance than that of common wheat MY11, as measured with antioxidant indexes and chlorophyll $a$ fluorescence. The flag leaves of both CN12 and CN17 maintained a relatively high antioxidant enzyme activity, chlorophyll content, and photosynthetic index and a low level of lipid degradation after $24 \mathrm{~h}$ of treatment with $10 \mu \mathrm{M}$ paraquat. The Stay-green wheat cultivars CN12 and CN17 had a high resistance to paraquat-induced photo-oxidative stress, which can potentially alleviate some of the damage induced by environment pollution.
\end{abstract}

\section{Introduction}

The herbicide paraquat (1,1'-dimethyl-4,4'-bipyridinium dichloride) has been continuously used as efficient herbicide in agriculture for over 50 years since it was invented in 1956 (Akinloye et al. 2011). Paraquat is a non-selective and fast-acting herbicide that affects all green tissues. It is also very strongly absorbed into the soil and thereby biologically deactivated (Roberts et al. 2002).

In light, paraquat affects the chloroplast by intercepting electrons from photosystem I (PSI) on the thylakoid membrane and creating a radical anion that is reoxidized by molecular oxygen to form superoxide $\left({ }^{-} \mathrm{O}_{2}{ }^{\bullet}\right)$ and other reactive oxygen species (ROS) (Chiang et al. 2008). The addition of $1 \mathrm{mM}$ paraquat to illuminated chloroplast suspensions increases the production of ${ }^{-} \mathrm{O}_{2}{ }^{\bullet}$ by up to ten-fold (Chia et al. 1981). Paraquat was used to simulate the ROS-induced damage caused by other environment stresses, such as drought, heat and salinity (Chia et al. 1981, Bhatt et al. 2011). The development of paraquat-resistant varieties could be an effective strategy to counteract various environmental stresses and ensure high crop yields.

Some stay-green plants (which delay senescence) were found to have high resistance to paraquat, and the mechanism of resistance seems to be similar in different plants (Chia et al. 1981, Falk et al. 2002). Superoxide dismutase (SOD) dismutate the superoxide to $\mathrm{H}_{2} \mathrm{O}_{2}$, which is removed by ascorbate peroxidase (APX), glutathione reductase (GR) and catalase (CAT) (Nehnevajova et al. 2012). Malondialdehyde (MDA) and chlorophyll levels are used as an indicator of lipid peroxidation and chloroplast damage, respectively (Khayatnezhad et al. 2011). The major mechanism by which stay-green plants adapt to various stresses such as drought, heat, and salt can be attributed to the ROS degradation system and the protection of the membrane (Allen 1995, Jena et al. 2009), but it is unknown how the stay-green plants adapt to paraquat stress.

*Author for correspondence: <lpglab@sicau.edu.cn>. 
The effects of paraquat stress on antioxidants and chlorophyll fluorescence in stay-green wheat was not reported. It is reported that the stay-green wheat lines Chuannong12 (CN12) and Chuannong17 (CN17) are highly resistant to paraquat-induced photo-oxidative stress.

A world-wide food crisis remains today due to the rapidly growing world population (Hodges 2005). Increasingly serious environmental damage can induce sharp reductions in crop productivity (Wang et al. 2010). The development of new cultivars with a high tolerance to environmental stress can ensure plant growth and yield. Some stay-green plants have been reported to resist various environment stresses that are associated with ROS. In this study, the resistance of stay-green wheat to environmental stress using paraquat treatment was investaged.

\section{Materials and Methods}

Wheat (Triticum aestivum L.) cultivars CN12 and CN17 exhibiting the stay-green phenotype based on several years of observation were grown in clay soil on the farm at the Ya'an Agricultural Research Station of Sichuan Agricultural University (27 $17^{\prime} \mathrm{N}, 120^{\circ} 16^{\prime} \mathrm{E}$ ) in Southwest China in the wheat growing season of 2010. Mianyang11 (MY11), an agronomic parent of both CN12 and CN17, was used as the control. Sufficient nutrients and water were supplied, and diseases were controlled throughout the growing season.

Flag leaves (10 cm length) from heading wheat of CN12, CN17 and MY11 were incubated with various concentrations $(0-500 \mu \mathrm{M})$ of paraquat and then illuminated at $400 \mu \mathrm{mol} / \mathrm{m}^{2} / \mathrm{sec}$ light intensity for $24 \mathrm{~h}$ before investigation.

Leaf samples were pulverized in liquid $\mathrm{N}_{2}$ using a mortar and pestle and then resuspended in $3 \mathrm{ml}$ of $100 \mathrm{mM}$ potassium phosphate buffer ( $\mathrm{pH}$ 7.5) containing $2 \mathrm{mM}$ ethylenediaminetetraacetic (EDTA), $50 \mathrm{mM} \mathrm{NaCl}, 1 \%$ polyvinyl polylpyrrolidone (PVPP) and $1 \mathrm{mM}$ ascorbic acid. The homogenate was centrifuged at $16000 \times \mathrm{g}$ for $15 \mathrm{~min}$ at $4^{\circ} \mathrm{C}$. Enzyme activity was determined spectrophotometrically: SOD at $560 \mathrm{~nm}$, APX at $290 \mathrm{~nm}$ and CAT at $240 \mathrm{~nm}$, as previously described (Lima et al. 2002, Lascano et al. 2003).

Leaf samples were pulverized in liquid $\mathrm{N}_{2}$ and homogenized with $2 \mathrm{ml}$ of cold $80 \%(\mathrm{v} / \mathrm{v})$ aqueous acetone and centrifuged twice at $16000 \times \mathrm{g}$ for $10 \mathrm{~min}$ at $4^{\circ} \mathrm{C}$. The combined supernatants were diluted ten-fold with $100 \%$ acetone, and the absorbance was measured at 645 and $663 \mathrm{~nm}$ (Spano et al. 2003). Chlorophyll $a$ and $b$ concentrations were calculated using the equations of Hill et al. (1985).

Leaf samples were pulverized in liquid $\mathrm{N}_{2}$, quartz sand and $3 \mathrm{ml}$ of $50 \mathrm{mM}$ potassium phosphate buffer ( $\mathrm{pH} 7.5$ ), and an equal volume (v) of $0.5 \%$ thiobarbituric acid was added. The complex was kept in boiling water for $30 \mathrm{~min}$ and centrifuged at $3000 \times \mathrm{g}$ for $10 \mathrm{~min}$. Absorbance was measured at 532 and $600 \mathrm{~nm}$, and the MDA content was determined using the absorption coefficient (Behera et al. 2002).

Chlorophyll $a$ fluorescence from PSII in flag leaves was measured with a modulated fluorescence meter (Li-6400-40 LCF, Li-Cor, USA). To ensure maximum photochemical efficiency of PSII, leaves were dark-adapted for at least $30 \mathrm{~min}$. The minimum fluorescence $\left(F_{0}\right)$ and maximum fluorescence $\left(F_{\mathrm{m}}\right)$ were measured in the dark-adapted leaves. The air temperature was $25^{\circ} \mathrm{C}$, the vapor pressure deficit (VPD) was $0.6 \mathrm{k} \mathrm{Pa}$, and the actinic light was $1000 \mu \mathrm{mol} / \mathrm{m}^{2} / \mathrm{s}$. To ensure efficient excitation capture of open PSII reaction centers, leaves were then measured in the light. Minimum fluorescence $\left(F_{0}^{\prime}\right)$ and maximum fluorescence $\left(F_{\mathrm{m}}^{\prime}\right)$ values under light were read as for $F_{\mathrm{o}}$ and $F_{\mathrm{m}}$ (Genty et al. 1989, Chen et al. 2010). The maximum photochemical efficiency of PSII in the dark-adapted leaves was calculated as the ratio of variable fluorescence $\left(F_{\mathrm{v}}=F_{\mathrm{m}}-F_{\mathrm{m}}\right)$ to $F_{\mathrm{m}}\left(F_{\mathrm{v}} / F_{\mathrm{m}}=F_{\mathrm{m}}-F_{\mathrm{o}} / F_{\mathrm{m}}\right)$. The efficiency of excitation capture by open PSII reaction centers was calculated as $F_{v}^{\prime} / F_{\mathrm{m}}^{\prime}=F_{\mathrm{m}}^{\prime}-F_{\mathrm{o}}^{\prime} / F_{\mathrm{m}}^{\prime}$. 


\section{Results and Discussion}

The malondialdehyde (MAD) content exhibited the same trend in MY11, CN12 and CN17 at different paraquat concentrations and decreased sharply after treatment with $0-5 \mu \mathrm{M}$ paraquat and then increased acutely with $10 \mu \mathrm{M}$ (Fig.1 A). There were minimal differences in MAD production between the cultivars at low paraquat concentrations $(0,5,10 \mu \mathrm{M})$. MY11 showed a higher increase than CN12 and CN17. The differences between MY11 and both CN12 and CN17 were significant. The MAD level of MY11 was 1.25 and 1.50 times higher than that of CN12 and CN17, respectively at the highest paraquat concentration $(500 \mu \mathrm{M})$. Although MY11 showed a dosedependent loss of chlorophyll, CN12 and CN17 maintained a high level of chlorophyll at paraquat concentrations lower than $100 \mu \mathrm{M}$, with the highest levels being observed with $5 \mu \mathrm{M}$ paraquat (Fig. 1B).

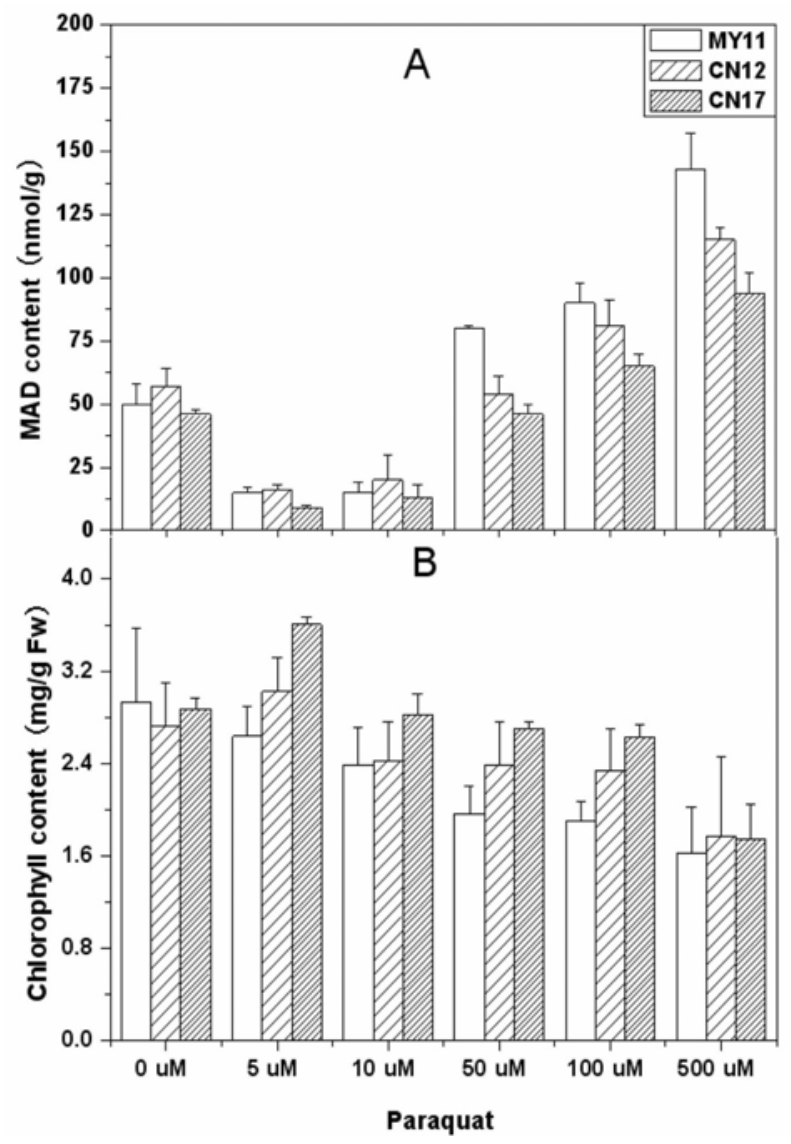

Fig. 1. The effect of paraquat treatment on (A) malondialdehyde (MAD) production and (B) chlorophyll content in flag leaves of the wheat cultivars MY11, CN12 and CN17. Duration of paraquat treatment and standard errors of the means are indicated. $(n=3)$.

Although the SOD activities of CN12 and CN17 flag leaves follow the same trend as that in MY11 at with various paraquat concentrations, the SOD activities remain relatively higher in CN12 and CN17. A decrease in activity with increasing paraquat concentration, except for a slight increase with $5 \mu \mathrm{M}$ paraquat was observed (Fig. $2 \mathrm{~A}$ ). 


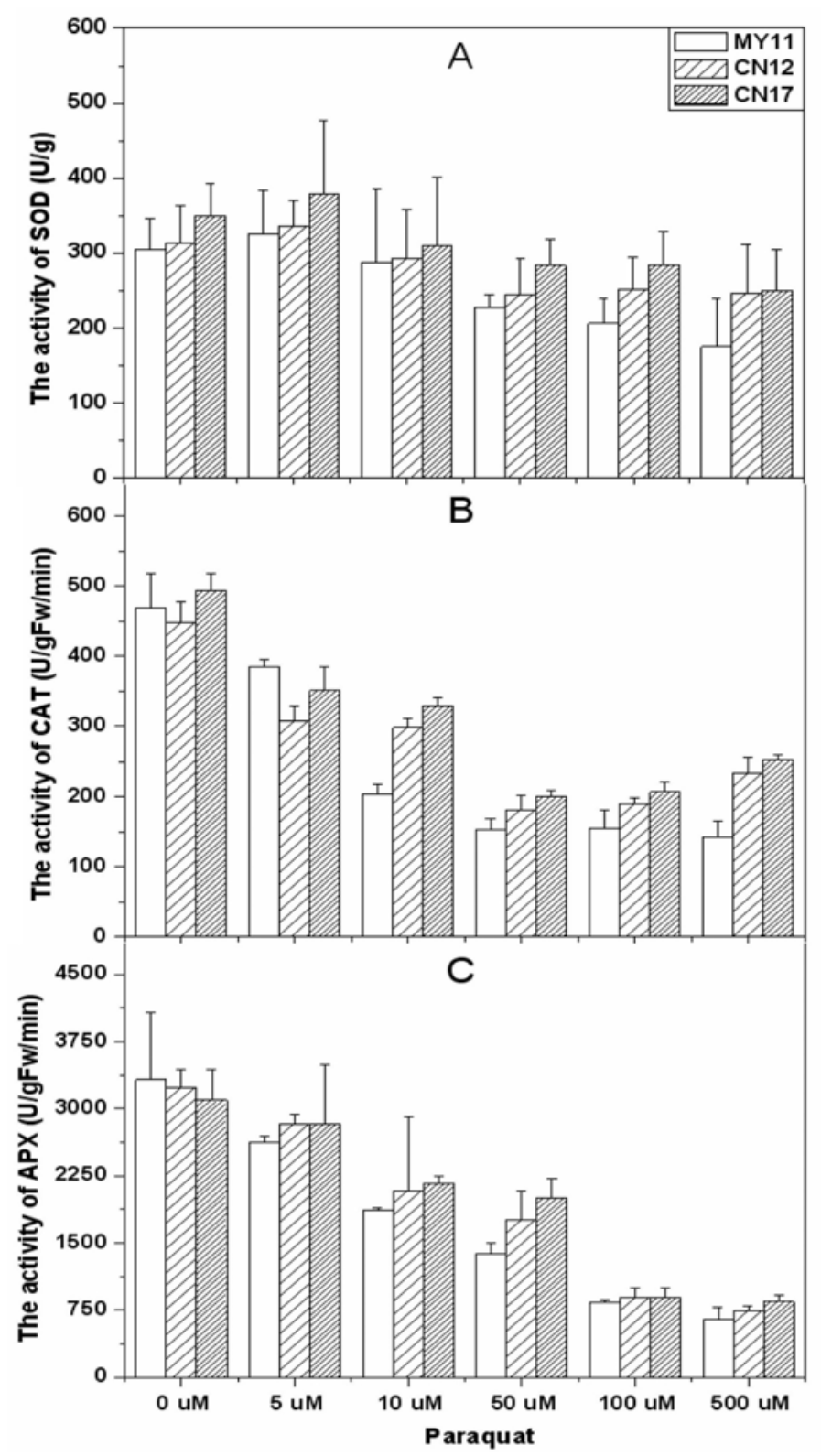

Fig. 2. Comparison of the effect of paraquat treatment on (A) superoxide dismutase (SOD), (B) catalase (CAT), and (C) ascorbate peroxidase (APX) from the flag leaves of the wheat cultivars, MY11, CN12 and CN17. Duration of paraquat treatment and standard errors of the means are indicated, $(n=3)$.

The catalase (CAT) activity of MY11 was found to decrease sharply with $5 \mu \mathrm{M}$ versus $10 \mu \mathrm{M}$ paraquat treatment, while the decrease in CN12 and CN17 mainly occurred with $10 \mu \mathrm{M}$ versus 50 $\mu \mathrm{M}$ paraquat treatment (Fig. 2 B). Although MY11 had slightly higher CAT activities than CN12 at $0 \mu \mathrm{M}$ and $5 \mu \mathrm{M}$ and $\mathrm{CN} 17$ at $5 \mu \mathrm{M}$, the activity of MY11 decreased to $204 \mathrm{U} / \mathrm{gFw} / \mathrm{min}$, while 
CN12 and CN17 maintained high levels of 298 and 329 U/gFw/min, respectively. A dosedependent decrease of APX activity is in all genotypes (Fig. 3B). MY11 had slightly higher APX activity at $0 \mu \mathrm{M}$ paraquat and lower activities at all other paraquat concentrations.

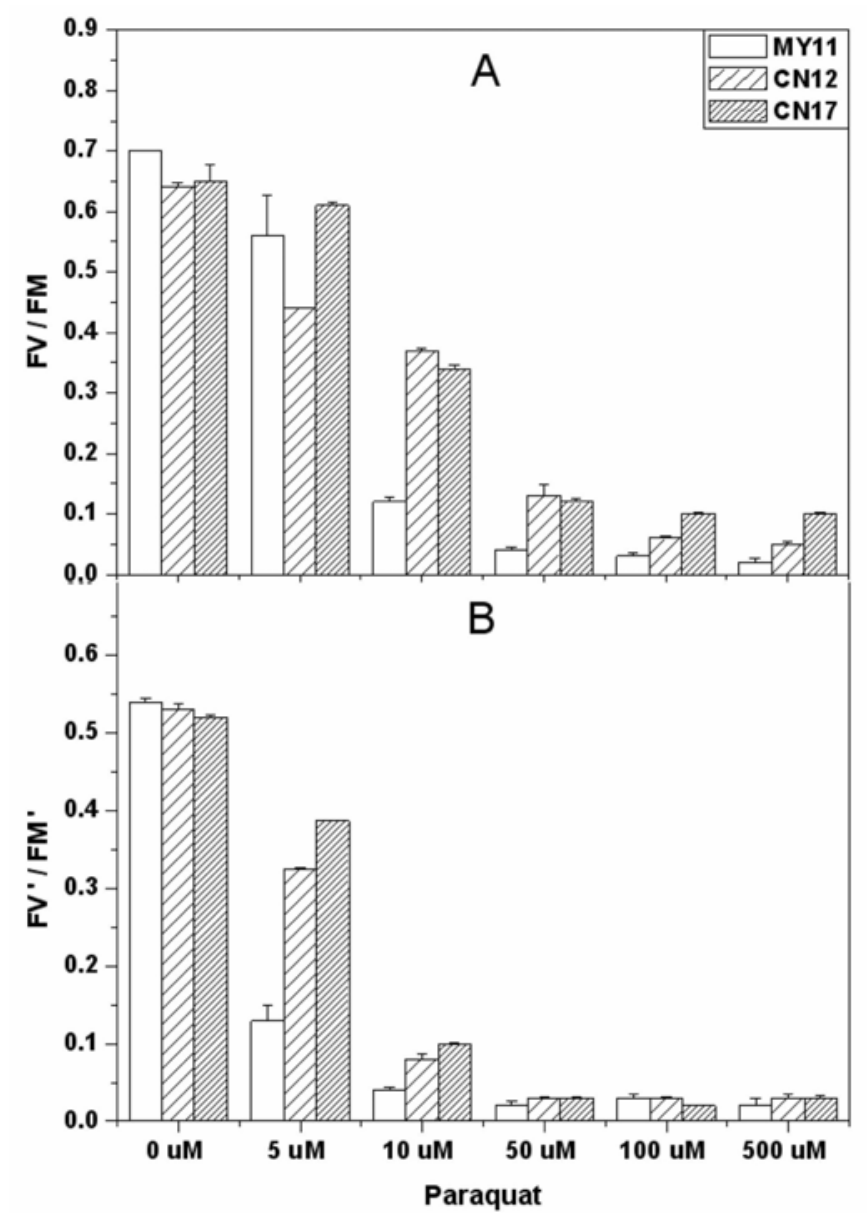

Fig. 3. The effect of paraquat treatment on (A) the maximal efficiency of PSII photochemistry (Fv/ Fm) and (B) the efficiency of excitation capture by open PSII reaction centers (F'v/F'm) of flag leaves of the wheat cultivars, MY11, CN12 and CN17. Duration of paraquat treatment and standard errors of the means are indicated. $(\mathrm{n}=3)$.

Antioxidant enzymes are present in the cell to protect against ROS that are induced by biotic and abiotic stresses (Razinger et al. 2007). The activities of these enzymes have been used to indicate the level of oxidative resistance (Allen 1995, Kuk et al. 2006). In general, CN12 and CN17 exhibited higher levels of SOD, CTA and APX activities at all paraquat concentrations (Fig. 2), indicating once again that these strains are more resistant to paraquat than MY11. SOD activity was found to decrease more slowly than that of APX and CAT. Because SOD dismutates the superoxide radical to $\mathrm{H}_{2} \mathrm{O}_{2}$ and APX and CAT metabolize $\mathrm{H}_{2} \mathrm{O}_{2}$ to $\mathrm{H}_{2} \mathrm{O}$ (Kuk et al. 2006), we can infer that the main ROS damage induced by paraquat comes from $\mathrm{H}_{2} \mathrm{O}_{2}$. 
The efficiency of PSII photosynthetic activity was measured with $F_{\mathrm{v}} / F_{\mathrm{m}}$ and $F_{v}{ }_{v} / F_{\mathrm{m}}^{\prime}$. The $F_{\mathrm{v}} /$ $F_{\mathrm{m}}$ and $F_{v}^{\prime} / F_{\mathrm{m}}^{\prime}$ ratios for MY11, CN12 and CN17 were not significantly different in $0 \mu \mathrm{M}$ paraquat, and MY11 was the most sensitive to paraquat (Fig.3). The $F_{\mathrm{v}} / F_{\mathrm{m}}$ ratio in MY11 was approximately $56 \%$ in $5 \mu \mathrm{M}$ paraquat and only $12 \%$ in $10 \mu \mathrm{M}$. In CN12 and CN17, this ratio was approximately 1.5 times higher in $10 \mu \mathrm{M}$ (Fig.3 A). The $F^{\prime}{ }_{v} / F^{\prime}$ m ratio in MY11 in $5 \mu \mathrm{M}$ was only $24 \%$ of that in $0 \mu \mathrm{M}$, whereas this ratio in CN12 and CN17 only decreased a little (Fig.3 B). All the $F_{\mathrm{v}} / F_{\mathrm{m}}$ and $F_{v}^{\prime} / F_{\mathrm{m}}^{\prime}$ ratios were very small with little variation at the 50, 100, and $500 \mu \mathrm{M}$ paraquat concentrations for all three genotypes. Paraquat first affects PSI, then damages the surrounding area and PSII (Lascano et al. 2003).

The stay-green cultivars CN12 and CN17 were found to exhibit significantly higher resistance to paraquat-induced photooxidative stress than their common agronomical parent MY11. In this study, CN17 performed better than CN12. Both strains harbor the wheat-rye 1BL/1RS translocated chromosome, and thus paraquat resistance may be associated with 1RS of rye.

\section{Acknowledgements}

The National Natural Science Foundation of China (No.30971787, 31271721 and 31171557) and the Provincial Science and Technology Foundation for Young Scientists of Sichuan, China (2010JQ0042) are duely acknowledged for their support.

\section{References}

Akinloye OA, Adamson I, Ademuyiwa O and Arowolo TA 2011. Occurrence of paraquat residues in some Nigerian crops, vegetables and fruits. J. Environ. Chem. Ecotoxicol. 3: 195-198.

Allen RD 1995. Dissection of oxidative stress tolerance using transgenic plants. Plant Physiol. 107: 10491054.

Behera PK, Mishra PC and Choudhury NK 2002. High irradiance and water stress induce alterations in pigment composition and chloroplast activities of primary wheat leaves. J. Plant Physiol. 159: 967-973.

Bhatt D, Negi M, Sharma P, Saxena SC, Dobriyal AK and Arora S 2011. Responses to drought induced oxidative stress in five millet varieties differing in their geographical distribution. Physiol. Mol. Biol. Plants 17: 347-353.

Chen JB, Liang Y, Hu XY, Wang XX, Tan FQ, Zhang HQ, Ren ZL and Luo PG 2010. Physiological characterization of 'stay green' wheat cultivars during the grain filling stage under field growing conditions. Acta. Physiol. Plant 32: 875-882.

Chia LS, Thompson JE and Dumbroff EB 1981. Simulation of the effects of leaf senescence on Membranes by treatment with paraquat. Plant Physiol. 67: 415-420.

Chiang YJ, Wu YX, Chiang MY and Wang CY 2008. Role of Antioxidative system in paraquat resistance of tall Fleabane (Conyza sumatrensis). Weed Sci. 56: 350-355.

Falk J, Krauß N, Dähnhard D and Krupinska K 2002. The senescence associated gene of barley encoding 4dioxygenase is expressed during oxidative stress. J. Plant Physiol. 159: 1245-1253.

Genty B, Briantais JM and Baker NR 1989. The relationship between the quantum yield of photosynthetic electron transport and quenching of chlorophyll fluorescence. Biochim. Biophys. Acta. 990: 87-92.

Hill CM, Pearson SA, Smith AJ and Rogers LJ 1985. Inhibition of chlorophyll systhesis in Hordeum vulgare by 3-amino 2, 3-dihydrobenzoic acid (gabaculin). Biosci. Rep. 5: 775-781.

Hodges J 2005. Cheap food and feeding the world sustainably. Livest. Prod. Sci. 92: 1-16.

Jena KB, Verlecar XN and Chainy GBN 2009. Application of oxidative stress indices in natural population of perna viridis as biomarker of environmental pollution. Marine Pollut. Bull. 58: 107-113.

Khayatnezhad M, Gholamin R, Somarin SJ and Mahmoodabad RZ 2011. The leaf chlorophyll content and stress resistance relationship considering in Corn cultivars (Zea mays). Adv. Environ. Bio. 5: 118-122. 
Kuk YI, Shin JS, Jung HI, Guh JO, Jung S and Burgos NR 2006. Mechanism of paraquat tolerance in cucumber leaves of various ages. Weed Sci. 54: 6-15.

Lascano HR, Melchiorre MN, Luna CM and Trippi VS 2003. Effect of photooxidative stress induced by paraquat in two wheat cultivars with differential tolerance to water stress. Plant Sci. 164: 841-848.

Lima ALS, DaMatta FM, Pinheiro HA Totola MR and Loureiro ME 2002. Photochemical responses and oxidative stress in two clones of Coffea canephora under water deficit conditions. Environ. Exp. Bot. 47: 239-247.

Nehnevajova E, Lyubenova L, Herzig R, Schröder P, Schwitzguébel JP and Schmülling T 2012. Metal accumulation and response of antioxidant enzymes in seedings and adult sunflower mutants with improved metal removal traits on a metal-contaminated soil. Environ. Exp. Bot. 76: 39-48.

Razinger J, Dermastia M, Drinovec L, Drobne D, Zrimec A and Koce JD 2007. Antioxidative responses of duckweed (Lemna minor L.) to short-term copper exposure. Environ. Sci. Pollut. Res. 14: 194-201.

Roberts TR, Dyson JS and Lane MC 2002. Deactivation of the biological activity of paraquat in the soil environment: a review of long-term environmental fate. J. Agr. Food Chem. 50: 3623-3631.

Spano G, Fonzo ND, Perrotta C, Platani C, Ronga G, Lawlor DW, Napier JA and Shewry PR 2003. Physiological characterization of "stay-green” mutants in durum wheat. J. Exp. Bot. 56: 1415-1420.

Wang X, Cai J, Jiang D, Liu FL, Dai TB and Cao WX 2010. Pre-anthesis high-temperature acclimation alleviates damages to flag leaf caused by post-anthesis heat stress in wheat. J. Plant Physiol. 168: 585-593.

(Manuscript received on 8 September, 2012; revised on 20 April, 2013) 